\title{
Não se mexe em time que está ganhando?
}

Alexandre Schwartsman*

Nesse sentido, essa política econômica é a mesma que a anterior e não deu bom resultado. (...) Apenas digo que, se essa política durar muito, como diz o próprio presidente Lula, é ruim porque prejudica a retomada do crescimento, a substituição de importações, as exportações.

Maria da Conceição Tavares, 21/abril/2003

Caiu a inflação. Portanto, mantiveram a política econômica dura que diziam que não iam manter, mas mantiveram. Contra meu ponto de vista. Perdi a parada, mas fico contente que tenha perdido, porque naquela altura ia ser complicado (...)

Maria da Conceição Tavares, 6/novembro/2009

\section{INTRODUÇÃO}

Em 2003, quando o governo Lula começou e ficou claro que a política econômica - definida pelo compromisso com uma meta de superávit primário, câmbio flutuante e metas para a inflação - iria persistir, não faltou quem previsse o fracasso desta orientação. A adoção do mesmo tripé que marcara a segunda parte do governo FHC era vista em certos círculos como uma concessão temporária à pressão dos mercados, mas que, passado algum tempo e estabelecida a esperada frustração com os resultados, logo seria revertida em favor de um arranjo alternativo.

Obviamente não foi o que aconteceu, pelo menos não até recentemente. Em que pese a clara deterioração do "tripé macroeconômico" no biênio final da administração, a manutenção das linhas de política econômica foi consistente tanto com a aceleração do crescimento quanto o aprofundamento da estabilidade. A despeito do forte impacto negativo da crise de 2008 sobre o produto efetivo, estimativas do crescimento potencial da economia se aceleraram visivelmente nos últimos 8 anos, atingindo valores da ordem de 4-4.5\% ao ano, comparados a números ao redor de 2-2.5\% no início do governo. Da mesma forma, os desvios da inflação com relação à meta, ainda que se mantendo majoritariamente do lado positivo, se reduziram sensivelmente.

\footnotetext{
* Doutor em economia pela Universidade da Califórnia em Berkeley. É economista-chefe do Grupo Santander Brasil e ex-diretor para Assuntos Internacionais do Banco Central do Brasil. As opiniões aqui expressas são pessoais e não devem ser tomadas como sendo do Grupo Santander. Endereço eletrônico: alexandre.schwartsman@ hotmail.com.
} 
Isto não quer dizer que não tenha havido problemas no que diz respeito à política econômica, em particular a política fiscal. Embora a dívida pública (tanto a bruta quanto a líquida, ainda que este último conceito se mostre crescentemente irrelevante) tenha caído, o peso do gasto público, em particular o gasto federal, aumentou consideravelmente. Mesmo sob o regime fiscal que parece ter prevalecido no período 2003-2008, caracterizado por superávits primários mais elevados que nos dois últimos anos, a política fiscal dificilmente poderia ser definida como restritiva à luz da expansão contínua do gasto.

No curto prazo tal comportamento implica uma tensão permanente entre as políticas fiscal e monetária, concretamente se traduzindo em taxas de juros mais elevadas do que as que teriam se materializado sob uma política fiscal mais austera, com repercussões, por exemplo, sobre a taxa de câmbio.

Numa perspectiva de mais longo prazo, a manutenção de um alto patamar do consumo público implica níveis mais baixos de poupança doméstica que, à luz da expansão do investimento (consistente com a aceleração do produto potencial), se reflete na necessidade crescente de poupança externa. Isto não se tornou um problema nos últimos anos graças a desenvolvimentos positivos da economia internacional que, mesmo depois da crise financeira, ainda permanecem, a saber: (a) a melhora expressiva de termos de troca, associada à forte alta de preços internacionais de commodities; e (b) a elevada liquidez internacional, que permite o financiamento a baixo custo dos déficits em conta corrente. Entretanto, ambas as condições podem se reverter em algum momento, o que criaria desafios consideráveis para a gestão de política econômica à frente.

Já no que se refere à política monetária, esta mostrou-se capaz de manter a inflação ao redor da meta, ainda que a distribuição dos desvios não aparente ser simétrica. Assim, muito embora as taxas de juros no Brasil sejam altas em comparação com outros países, não parecem se traduzir em taxas de inflação sistematicamente inferiores à meta, este sim um sinal de exagero do ponto de vista de condução da política monetária.

Adicionalmente, há evidência que as taxas neutras de juros no Brasil seriam mesmo elevadas, talvez em torno de $8 \%$ ao ano segundo nossas estimativas mais recentes. Cabe reconhecer, contudo, que possíveis reduções adicionais por conta da crise internacional não podem ser capturadas nas nossas amostras. Isto se traduz no comportamento do consumo que, embora pareça reagir conforme o esperado às alterações nas taxas de juros, cresce mesmo face a níveis relativamente elevados de juros. Posto de outra forma, a persistência de taxas altas de juros não parece ter impedido o crescimento da demanda interna mais rápido que o crescimento do produto. 
Finalmente, ainda que taxas de juros apresentem o efeito esperado sobre a taxa de câmbio, os fatores determinantes do comportamento do real não são domésticos: impactos associados a preços internacionais de commodities e ao valor global do dólar dominam os resultantes de mudanças nas taxa domésticas de juros.

Em suma, o arranjo de política macroeconômica no Brasil entregou o que prometeu: crescimento mais alto, com estabilidade; e poderia ter entregue mais se certos aspectos, em particular no campo fiscal, tivessem sido devidamente aprofundados. No entanto, há indicações cada vez mais claras de deterioração desta estrutura, apesar dos seus resultados positivos. A política fiscal, em particular, se tornou ainda mais expansionista, e crescem as dúvidas acerca do grau de compromisso do Banco Central no que se refere à meta para a inflação.

Quando chegamos ao fim do governo Lula, as bases que foram lançadas, com grande esforço, para o novo ciclo de crescimento sustentável estão mais ameaçadas do que jamais estiveram. A despeito do seu sucesso incontestável, podemos ter observado o ocaso do tripé macroeconômico no Brasil.

\section{POLÍTICA FISCAL}

Examinada pela ótica da sustentabilidade da dívida, à qual nos acostumamos para julgar a política fiscal, o êxito do governo Lula é claro: a dívida líquida do setor público, que atingira um pico próximo a 57\% do PIB no terceiro trimestre de 2002, caiu para pouco mais de 41\% do PIB no quarto trimestre de 2010 e há declarações acerca da intenção da nova administração no sentido de reduzir esta razão para um patamar em torno de 30\% do PIB em 2014. O sucesso pode não ser tão claro quando observamos o desempenho da dívida bruta, que caiu de valores ao redor de $74 \%$ do PIB para $67 \%$ do PIB no mesmo período ${ }^{1}$, mas, ainda assim, sugere que a ênfase dada à redução da dívida federal rendeu frutos.

Há, adicionalmente à queda da relação dívida-PIB, uma mudança radical no seu perfil em várias dimensões. No que se refere à moeda na qual a dívida foi contratada, houve um deslocamento da dívida denominada em moeda estrangeira (tanto dívida externa como interna, incluído derivativos cambais) para dívida denominada em moeda nacional. Com isto, a sensibilidade da dívida (líquida) às variações cambiais trocou de sinal: enquanto no pior momento de 2002 uma desvalorização de $1 \%$ da taxa de câmbio elevaria a relação dívida-PIB em $0,3 \%$ do PIB, atualmente a mesma desvalorização reduæiria esta relação em $0,1 \%$ do PIB.

1 Aqui nos referimos ao conceito antigo de dívida bruta, já que, pela nova definição (que exclui da dívida federal os títulos em poder do Banco Central que não tenham sido usados como lastro para operações compromissadas), a dívida alcançaria cerca de 60\% do PIB. Como, porém, não há estatísticas sobre o valor da nova definição de dívida bruta antes de 2007, para fins de comparação intertemporal temos que usar a definição anterior. 
GRÁFICO 1 - DÍVIDA BRUTA (\% DO PIB) E SENSIBILIDADE DA DÍVIDA LÍQUIDA AO CÂMBIO (\% DO PIB)
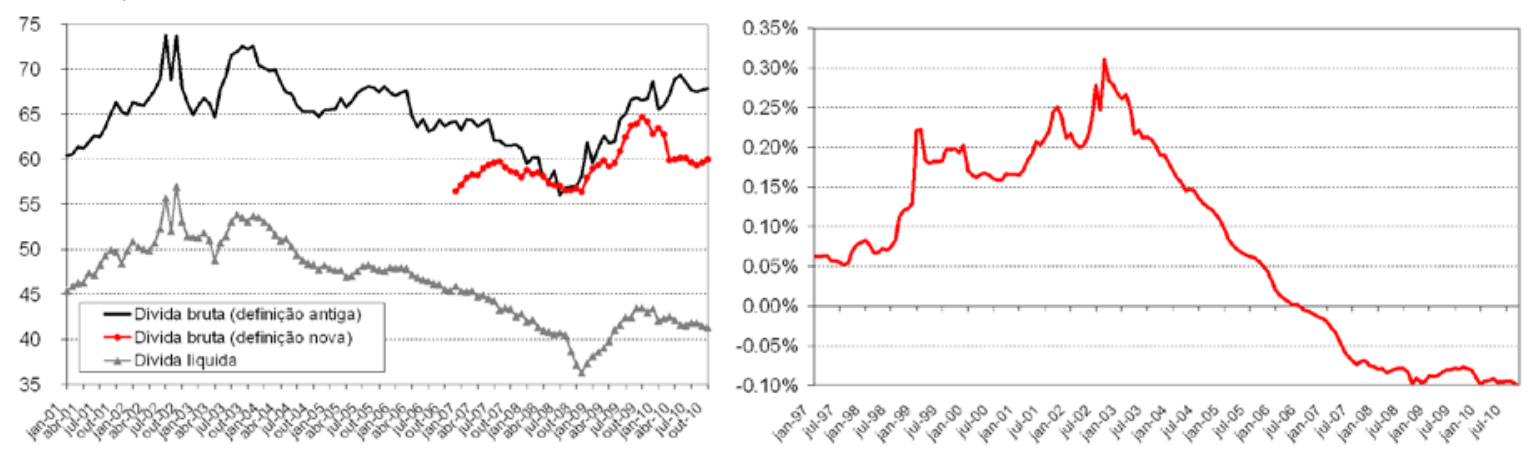

FONTES: BCB, Secretaria do Tesouro, IBGE.

Com isto foi quebrado um importante elo de realimentação de choques externos. De fato, quando a sensibilidade era positiva, um dado choque externo (por exemplo, queda do preço de commodities, ou uma piora das condições internacionais de financiamento) deflagrava um processo perverso. A desvalorização cambial implicava aumento da dívida pública, que, por sua vez, alimentava receios quanto à sua sustentabilidade, levando a elevação da avaliação de risco soberano, que, finalmente, se traduzia em nova rodada de desvalorização cambial, realimentando o processo.

Havia, pois, um mecanismo que ampliava os efeitos de choques externos, cujas consequências para as políticas fiscal e monetária também eram severas, impedindo, na prática, a adoção de políticas anticíclicas, além de afetar o próprio mecanismo de ajuste do câmbio flutuante. Com efeito, em face de uma deterioração do risco soberano não era possível, mesmo em resposta a um choque externo negativo, usar a política fiscal de maneira anticíclica. Pelo contrário, tornava-se necessário elevar o superávit primário em períodos de estresse justamente para compensar os efeitos negativos da elevação dos spreads de risco.

Da mesma forma, o medo da flutuação, por conta da contaminação dos passivos (públicos e privados) denominados em moeda estrangeira, requeria que a política monetária fosse também utilizada, em alguma medida, para moderar a desvalorização da moeda. Adicionalmente, como os mecanismos de ampliação do choque implicavam desvalorização persistente da taxa de câmbio, além do que seria de se esperar apenas pelo efeito do choque externo, as expectativas de inflação reagiam vigorosamente aos movimentos da moeda, ampliando também o repasse do câmbio para preços domésticos, processo que também impedia a execução de uma política monetária contracíclica.

Assim, na medida em que a sensibilidade da relação dívida-PIB mudou de sinal, em grande parte por conta da acumulação de reservas, este mecanismo foi quebrado. Deste modo, 
quando a moeda se desvalorizou em face da crise financeira no quarto trimestre de 2008, a relação dívida-PIB caiu aceleradamente, permitindo que a política fiscal assumisse uma postura anticíclica². Além disto, como o repasse da desvalorização foi menor, em parte devido à percepção de uma desvalorização menos persistente, também a política monetária pôde ser acionada.

GRÁFICO 2 - GASTO FEDERAL (R\$ MILHÕES DE OUTUBRO DE 2010) E CARGA TRIBUTÁRIA X GASTO PÚBLICO (\% DO PIB)
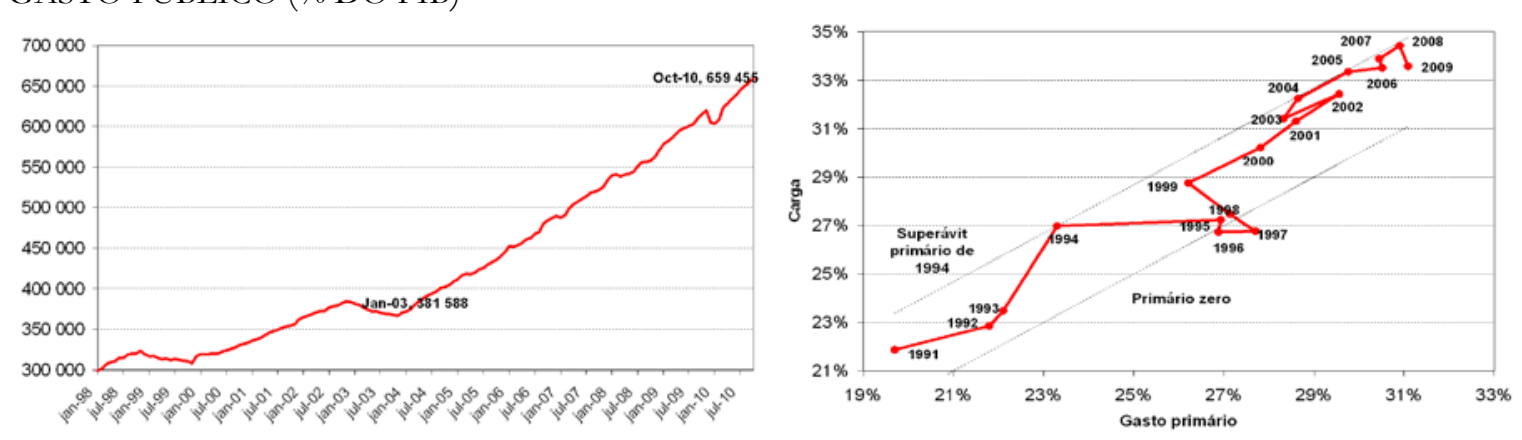

FONTES: BCB, Secretaria do Tesouro, IBGE, Secretaria da Receita do Brasil.

Entretanto, se houve progresso na questão do endividamento público, ao mesmo tempo não há como afirmar que a política fiscal tenha sido contracionista. Ao contrário, o gasto público cresceu aceleradamente no período. Medido a preços constantes de outubro de 2010, o gasto federal (excluindo transferências a estados e municípios) aumentou de $\mathrm{R} \$ 380$ bilhões para $\mathrm{R} \$ 660$ bilhões, equivalente a uma taxa média de expansão pouco acima de $7 \%$ ao ano acima da inflação ${ }^{3}$.

Quando mudamos o foco de análise para o setor público consolidado (União, estados e municípios, sem empresas estatais), percebemos desempenho semelhante. Estimativas do gasto público primário consolidado, obtidas a partir da diferença entre a carga tributária e o superávit primário ${ }^{4}$ estimado pelo Banco Central, mostram uma expansão persistente do gasto, de 28,3\% do PIB em 2003 para 31,9\% do PIB em 2009, devidamente acompanhada pelo crescimento da carga tributária.

2 A redução da dívida abriu a possibilidade de uma política contracíclica. Isto não significa que a política fiscal efetivamente adotada foi contracíclica, haja vista que, como veremos, não faltam indicações que o superávit primário tenha sido reduzido de forma persistente, permanecendo abaixo dos valores registrados no período 2002-2008 mesmo quando a economia já se encontrava muito além do processo de recuperação.

3 Note que este resultado é bastante afetado pela contração do gasto em 2003. Medida a partir de dezembro daquele ano, a taxa de crescimento média da despesa federal é 8,7\% ao ano acima da inflação.

4 É importante destacar que tais estimativas muito provavelmente subestimam o verdadeiro nível do gasto primário no país. Há, além dos tributos, outras fontes de receita para o governo, como concessões ou dividendos recebidos de empresas estatais. $\mathrm{Na}$ medida em que estas outras receitas não estão inclusas no cálculo, porque não temos informações completas a seu respeito, a estimativa do gasto, obtida pela diferença entre a receita tributária e o superávit primário, é necessariamente inferior ao valor real. Apenas para o governo federal, estas receitas nãotributárias representaram, em média, 2,1\% do PIB entre 1997 e 2009. 
Esta postura expansionista da política fiscal foi acentuada nos últimos anos. Sob a desculpa de execução de uma política fiscal contracíclica o governo federal elevou gastos permanentes, tanto em 2009 como em 2010, reduzindo seu superávit primário de maneira persistente. Isto pode não transparecer nos números oficiais, tendo em vista o crescimento de receitas nãofiscais, em particular as obtidas pela cessão onerosa de direitos de exploração de petróleo, mas, uma vez que se ajuste o desempenho fiscal do governo federal, retirando tanto receitas quanto despesas (por exemplo, o Fundo Soberano e a capitalização da Petrobras), obtemos imagem bastante distinta do desempenho fiscal.

GRÁFICO 3 - SUPERÁVIT PRIMÁRIO DO GOVERNO FEDERAL (\% DO PIB) E SUPERÁVIT PRIMÁRIO AJUSTADO X HIATO DO PRODUTO.
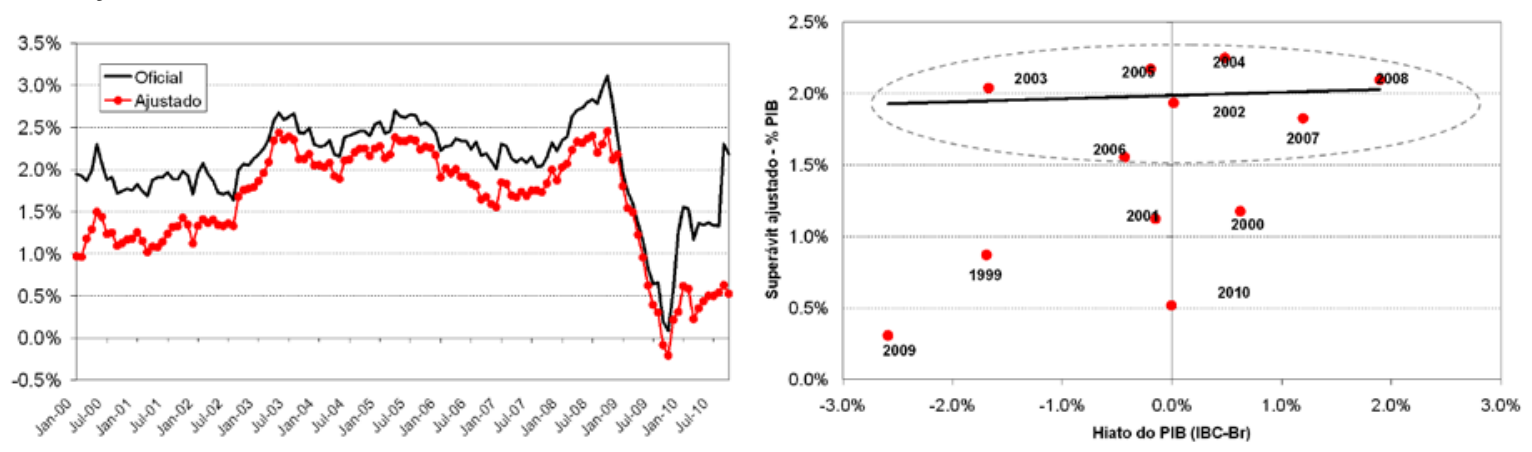

FONTES: BCB, Secretaria do Tesouro, IBGE.

Com efeito, enquanto os números oficiais mostram o superávit primário de volta ao patamar em que se encontrava no período 2003-2008 (entre 2-2,5\% do PIB), após uma redução temporária em 2009 e parte de 2010 (o que caracterizaria uma política anticíclica), os dados ajustados expõem uma redução persistente do superávit primário. Medido sob a hipótese da economia operando a plena carga (i.e., com o hiato de produto a zero) observa-se queda do superávit primário da ordem de $1,5 \%$ entre 2008 e $2010^{5}$, revelando uma expansão fiscal bastante considerável.

Assim, se, no que tange à dimensão de solvência, a política fiscal tem conseguido manter a dívida pública sob controle, e (provavelmente) em queda, na gestão de demanda doméstica os desenvolvimentos não têm sido tão encorajadores, para dizer o mínimo.

No curto prazo as implicações dizem respeito aos conflitos entre política monetária e fiscal. Dada uma meta para a inflação, uma expansão fiscal mais vigorosa requer, tudo o mais constante, uma política monetária mais apertada para manter a inflação na meta. Vale dizer, a expansão fiscal persistente (agora acelerada) implica uma trajetória de taxas de juros mais elevadas do que as vigorariam caso a expansão fiscal não tivesse ocorrido, com implicações claras $5 \mathrm{Na}$ verdade os 12 meses até setembro de 2010. 
também para a trajetória de câmbio nominal e real ${ }^{6}$.

Em prazo mais longo, a questão se torna o conflito entre o consumo do governo e a expansão do investimento privado. Historicamente se observa que a expansão do investimento relativamente ao PIB corresponde à redução das exportações líquidas e, em particular, que observações de investimento superiores a 17,5\% do PIB têm como contrapartida, quase sempre, exportações líquidas negativas, indicando o nível reduzido da poupança doméstica.

GRÁFICO 4 - INVESTIMENTO X EXPORTAÇÕES LÍQUIDAS (S. A.) E BRASIL (-) MÉDIA AMÉRICA LATINA $^{*}$
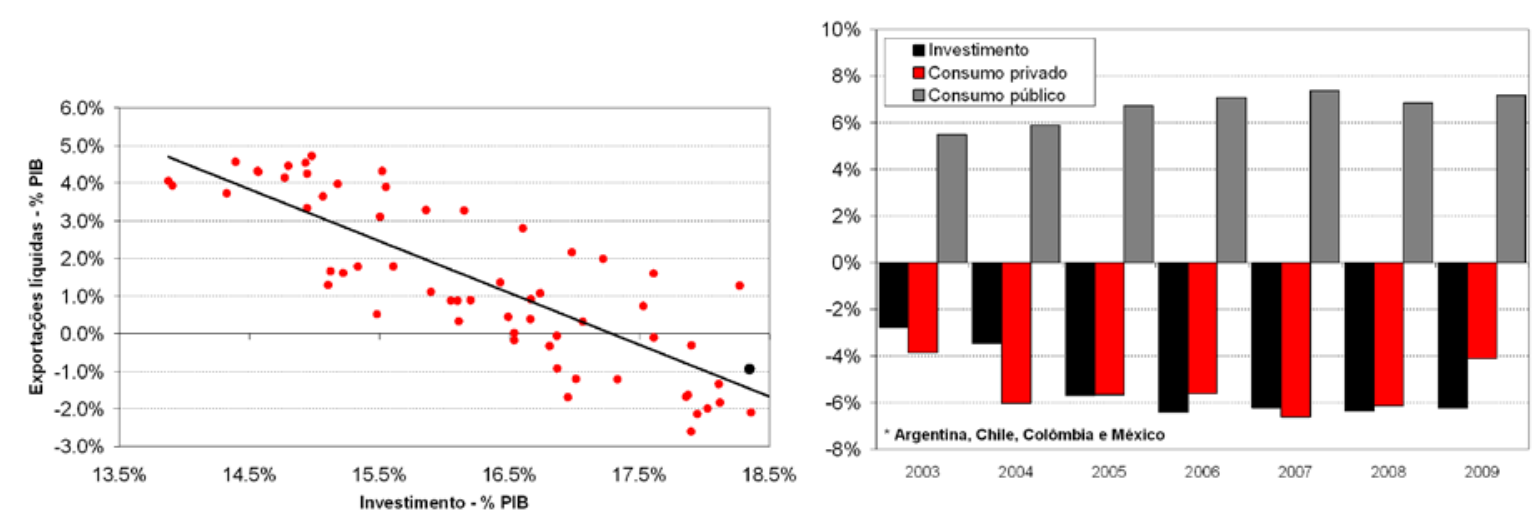

FONTES: IBGE, INDEC, INE, Banco de la República e INEGI.

O baixo nível de poupança, contudo, não parece resultar de consumo privado particularmente elevado. Tomando como referência outros países da América Latina ${ }^{7}$, cujo nível de desenvolvimento e raízes culturais são semelhantes aos nossos, não há indicação que o consumo privado no Brasil seja muito alto. Pelo contrário, o consumo privado brasileiro tem ficado entre $4 \%$ e $6 \%$ do PIB abaixo da média latino-americana ${ }^{8}$. Por outro lado, o consumo público no Brasil tem ficado persistentemente acima da média regional, aparecendo, portanto, como o suspeito mais provável para entender a reduzida poupança doméstica.

Posto de outra forma, o gasto público persistentemente elevado implica que a expansão do investimento só possa ser financiada pela redução consistente das exportações líquidas. O problema tem sido consideravelmente atenuado pelo ganho expressivo de termos de troca observado nos últimos anos e acelerado particularmente em 2010.

De fato, se definirmos como ponto de referência a média histórica (ajustada pela in-

6 Como o trade-off entre política monetária e fiscal se dá ao longo de uma meta constante de inflação, alterações no câmbio nominal resultantes deste trade-off são também alterações na taxa real de câmbio.

7 Argentina, Chile, Colômbia e México.

8 A rigor, como as taxas de juros são mais altas no Brasil do que nestes países, não podemos concluir, apenas pela razão consumo-PIB, que os brasileiros são mais (ou menos) pacientes que seus vizinhos latino-americanos. De qualquer forma, não parece haver grande distorção no nível de consumo brasileiro relativamente aos seus pares. 
GRÁFICO 5 - TERMOS DE TROCA (2006=100) E GANHO DE TERMOS DE TROCA (\% DO PIB)
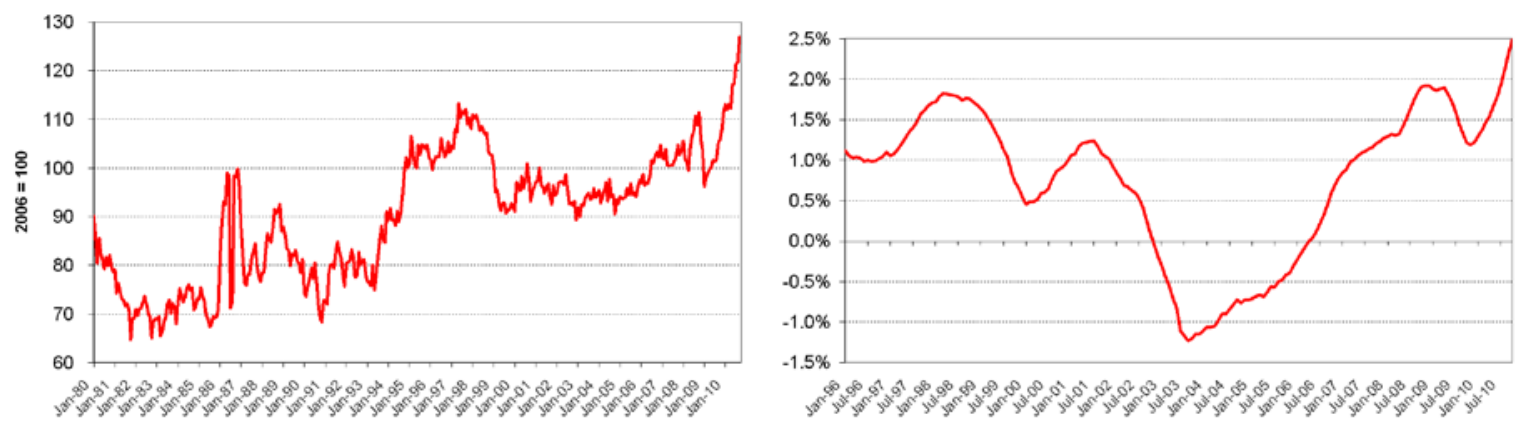

FONTES: Funcex, BCB.

flação americana) dos preços de exportação e importação, e supusermos adicionalmente que a evolução observada das quantidades exportadas e importadas se mantivesse mesmo num cenário caracterizado por piores termos de troca (portanto taxa de câmbio mais fraca), é possível mostrar que, nos 12 meses até outubro deste ano, ao invés de um superávit comercial de US\$18 bilhões, o país teria registrado um déficit de US\$ 32 bilhões, ou seja, os termos de troca teriam implicado um ganho de US\$ 50 bilhões, ou cerca de 2,5\% do PIB.

A evolução destas estimativas dos ganhos associados aos termos de troca sugere que o país teria saído de uma situação na qual havia perdas (quase 1,5\% do PIB) em meados de 2003 para os 2,5\% do PIB em 2010, um ganho marginal de 4\% do PIB. Esta melhora parece ter desempenhado papel central em termos de permitir a expansão do investimento 9 que, por sua vez, se traduziu não apenas em crescimento mais rápido do produto, mas, crucialmente, também em indicações que o próprio crescimento potencial teria se acelerado, situando-se correntemente em patamar próximo a $4-4,5 \%$ ao ano.

\section{GRÁFICO 6 - CRESCIMENTO DO PIB E ESTIMATIVAS DE CRESCIMENTO DO PIB POTENCIAL}
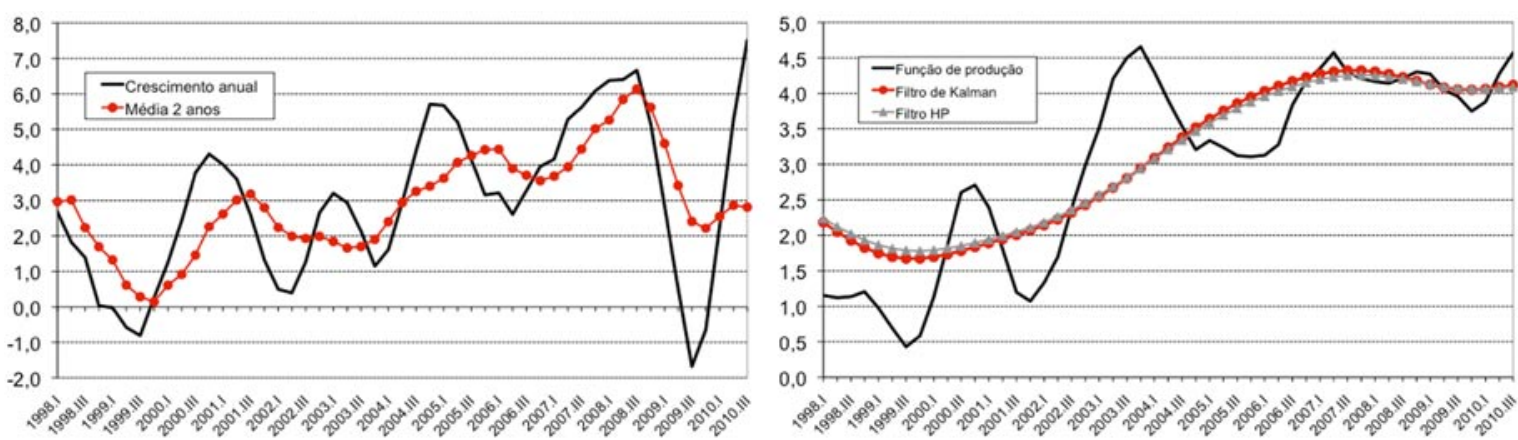

FONTES: IBGE e estimativas de Cristiano Souza ${ }^{10}$ e Alexandre Schwartsman.

9 A taxa de investimento (dessazonalizada), que caíra para 14\% do PIB em 2003, subiu até 19\% do PIB no terceiro trimestre de 2008, quando a crise internacional teve impacto fortemente negativo. No terceiro trimestre de 2010, contudo, a taxa de investimento retornou ao patamar de 19\% do PIB.

10 As estimativas de PIB potencial pelos métodos de função de produção e filtro de Kalman são de Cristiano Souza (a quem agradeço). As estimativas produzidas pela aplicação de um filtro HP são do autor. 
No entanto, não parece razoável contar com ganhos comparáveis no futuro para garantir a expansão do investimento sem efeitos negativos sobre o déficit em conta corrente. Neste contexto, o ajuste fiscal se faz crescentemente necessário para viabilizar uma taxa maior de investimento (e, portanto, do produto potencial) sem expansão correspondente da poupança externa.

Nos últimos anos, portanto, a política fiscal deixou de ser apenas uma questão relacionada à sustentabilidade da dívida pública para se tornar um problema associado à gestão da demanda no curto prazo e, no médio e longo prazos, na forma de conciliar o crescimento do investimento com a poupança domestica, isto é, uma discussão associada à aceleração do ritmo de expansão econômica. Enquanto a sustentabilidade parece estar sendo tratada pelos desenvolvimentos recentes da política fiscal, as duas outras questões ainda requerem uma solução que não parece estar à vista.

\section{POLÍTICA MONETÁRIA}

A persistência de taxas altas de juros no Brasil é uma questão ainda não respondida. A despeito de uma queda expressiva nos últimos anos, a taxa real de juros permanece em patamar ainda elevado: a taxa Selic, deflacionada pelas expectativas de inflação 12 meses a frente, coletadas pela pesquisa Focus do Banco Central, se encontrava pouco superior a 5\% ao ano em novembro de 2010, enquanto a taxa prefixada para um ano (o swap pré-CDI para 360 dias), igualmente deflacionada pela inflação esperada registrava um valor pouco inferior a $6 \%$ ao ano. Trata-se, a bem da verdade, de valores muito menores do que os observados há alguns anos, quando taxa reais de juros de dois dígitos faziam parte da paisagem brasileira, mas, ainda assim, taxas reais de juros no Brasil saltam aos olhos em qualquer comparação internacional que se faça.

GRÁFICO 7 - TAXAS DE JUROS (-) INFLAÇÃO ESPERADA 12 MESES À FRENTE

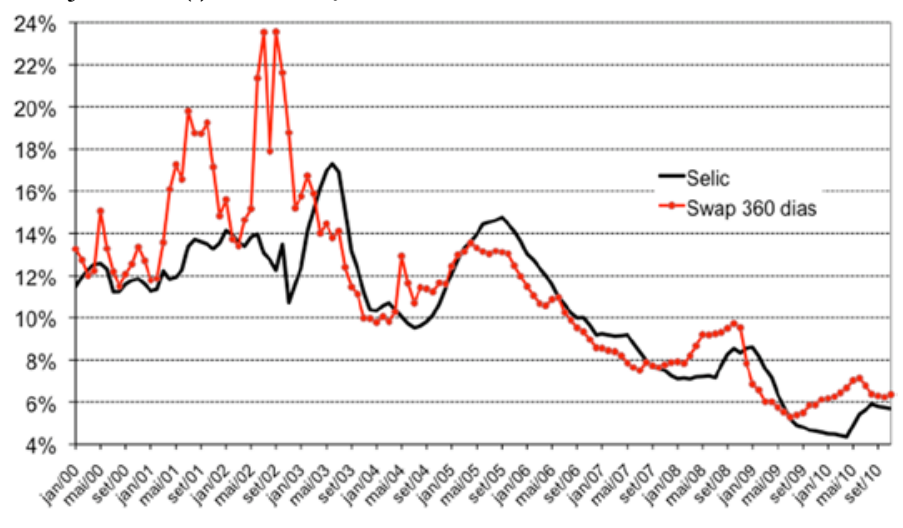

FONTE: BCB. 
Entretanto, no que se refere ao desempenho de política monetária relativamente ao seu objetivo (a meta para a inflação), não há qualquer evidência que as taxas de juros no Brasil tenham sido exageradas. Fosse este o caso, teríamos necessariamente que observar a inflação sistematicamente abaixo da meta, mas, como pode se ver, isto está longe de ser o caso.

GRÁFICO 8 - IPCA X META E DISTRIBUIÇÃO DOS DESVIOS DE INFLAÇÃO (2004-2010)
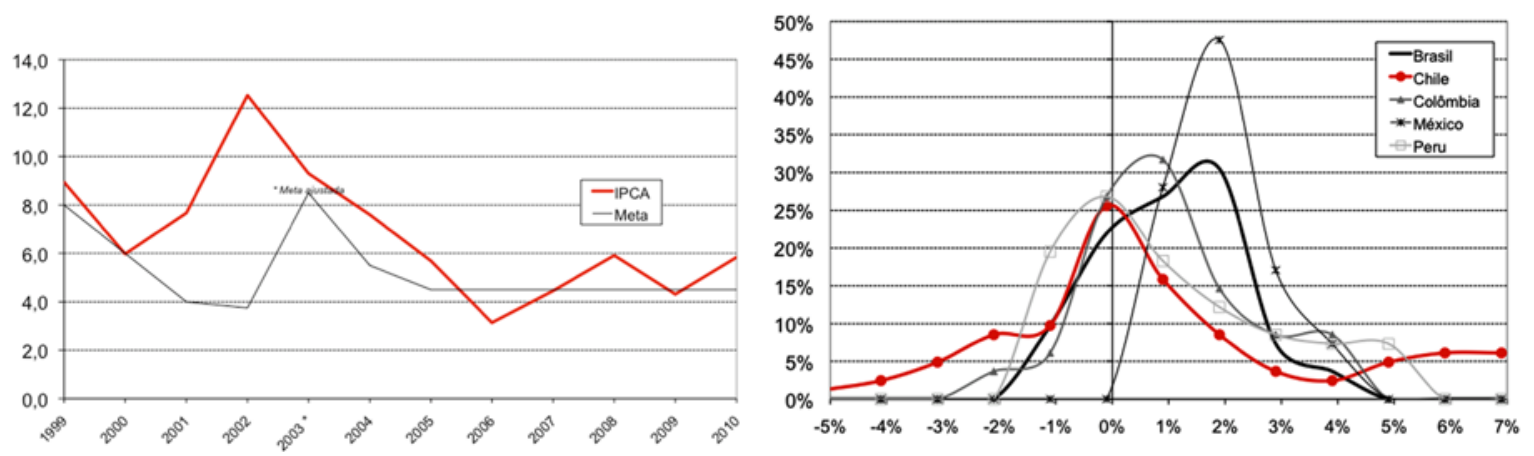

FONTES: IBGE, BCB, Banco de Chile, Banco de La Republica, Banxico, Banco de Reserva Del Peru.

De fato, ainda que os desvios da inflação com relação à meta tenham sido menores no período 2003-2010 ${ }^{11}$ e, em alguns casos (2006 e 2009) a inflação tenha ficado abaixo da meta, não há como identificar um desvio sistemático para baixo. Ao contrário, seguindo o desempenho do desvio da inflação com relação à meta em janelas móveis de 12 meses de janeiro de 2004 a outubro de 2010 observamos que a distribuição dos desvios fica significativamente à direita de zero, enquanto a moda da distribuição se encontra no intervalo $+1 \% a+2 \%$.

Tal desempenho, ainda que não o pior na amostra dos 5 países latino-americanos seguidores do regime de metas para a inflação pesquisados (Brasil, Chile, Colômbia, México e Peru), é nitidamente inferior ao apresentado por Chile e Peru. A despeito de uma volatilidade maior, em ambos os casos a moda dos desvios fica ao redor de zero. Por qualquer ângulo que se olhe, não há como identificar desvios sistemáticos para baixo com relação à meta no Brasil; se houve algum desvio sistemático no período 2004-2010, ele parece ter sido para cima da meta.

Esta observação, tomada em conjunto com a persistência de taxas reais de juros elevadas no país, sugere que a taxa neutra de juro no Brasil, ainda que provavelmente cadente, é bastante elevada. E, de fato, nossas estimativas indicam que isto parece ser verdade.

Para ver isto, considere que o BC obedeça uma função de reação no espírito da Regra de Taylor, escolhendo a taxa de juros de acordo com desvios da inflação esperada com relação à meta e do hiato de produto relativamente a zero. Concretamente, o $\mathrm{BC}$ escolheria a taxa de

11 Para 2010, como já sabemos a inflação nos primeiros 11 meses do ano (5,25\%), usamos a mediana da projeção dos Top 5 de curto prazo da pesquisa Focus mais recente como previsão para a inflação de dezembro $(0,56 \%)$, o que implica 5,84\% para o IPCA desse ano. 
juros $\left(i_{t}\right)$ como um desvio com relação à taxa nominal neutra de juros (definida como a taxa real de juros acrescida da inflação esperada) refletindo os desvios acima, na seguinte forma:

$$
i_{t}=\bar{r}+\pi_{t}+a_{\pi}\left(\pi_{t}-\bar{\pi}_{t}\right)+a_{y} y_{t}
$$

onde $a_{\pi}$ e $a_{y}$ refletem respectivamente os pesos do desvio da inflação e do hiato de produto na decisão de taxa de juros ${ }^{12}$, enquanto $\bar{\pi}$ é a meta para a inflação e $\bar{r}$ a taxa real neutra de juros. Rearranjando os termos de (1) obtemos a seguinte expressão:

$$
i_{t}=\bar{r}+\left(1+a_{\pi}\right) \pi_{t}-a_{\pi} \bar{\pi}_{t}+a_{y} y_{t}
$$

No entanto, na prática bancos centrais raramente ajustam a taxa de juros num único movimento. Tipicamente por conta de incertezas inerentes à gestão de política monetária, o banco central costuma agir de forma gradualista, ajustando a taxa de juros ao longo de vários passos, enquanto obtém informação adicional para calibrar a política monetária. Há, desta forma, certo grau de inércia na escolha da taxa de juros, que poderia então ser descrita como:

$$
i_{t}=\rho i_{t-1}+(1-\rho)\left[\bar{r}+\left(1+a_{\pi}\right) E_{t} \pi_{t+1}-a_{\pi} \bar{\pi}_{t}+a_{y} y_{t}\right]
$$

onde $\rho$ captura o grau de inércia. Caso $\rho=1$ a taxa de juros é constante (a inércia seria total) e não responderia aos desvios da inflação e do hiato de produto; caso $\rho=0$ estamos de volta à formulação (1a), onde o ajuste é feito num único movimento (não haveria inércia).

Assim, se o BC segue uma regra do tipo (2) para determinar a taxa de juros podemos estimar uma equação na forma:

$$
i_{t}=\lambda i_{t-1}+a_{0}+a_{1} E_{t} \pi_{t+1}+a_{2} \bar{\pi}_{t}+a_{3} y_{t}+\varepsilon_{t}
$$

para recuperar os parâmetros de interesse. Em particular, a taxa de juros real neutra seria dada por:

12 Seguindo o princípio de Taylor, espera-se que o coeficiente associado ao desvio da inflação esperada seja positivo para garantir estabilidade da inflação. 


$$
\bar{r}=a_{0} /(1-\lambda)
$$

Poupando os leitores dos detalhes da estimação ${ }^{13}$, mostramos os resultados obtidos para a taxa neutra de juros para diferentes amostras. Todos os períodos amostrais se encerram em outubro de 2009, mas o mais longo deles começa em janeiro de 2002, enquanto o mais curto começa em janeiro de 2007. A ideia por trás desta abordagem consiste em tentar avaliar se nos períodos mais recentes haveria alguma evidência de queda da taxa neutra.

TABELA 1 - ESTIMATIVAS DA TAXA NEUTRA DE JUROS REAL NO BRASIL

\begin{tabular}{lr|r|r|r|rrr}
\hline & \multicolumn{7}{c}{ Início da amostra } \\
\cline { 2 - 7 } & \multicolumn{2}{c}{$\mathbf{2 0 0 2}$} & $\mathbf{2 0 0 3}$ & $\mathbf{2 0 0 4}$ & $\mathbf{2 0 0 5}$ & $\mathbf{2 0 0 6}$ & $\mathbf{2 0 0 7}$ \\
\hline Taxa neutra (+) 1 desvio-padrão & 10,8 & 16,5 & 9,4 & 11,1 & 8,9 & 8,7 \\
Taxa neutra estimada & 8,9 & 8,8 & 8,6 & 9,0 & 8,3 & 8,2 \\
Taxa neutra (-) 1 desvio-padrão & 7,1 & 1,7 & 7,8 & 6,9 & 7,7 & 7,7 \\
\hline
\end{tabular}

FONTE: Alexandre Schwartsman e Cristiano Souza (The Rescue of the Kobayashi Maru).

Nossas estimativas sugerem uma redução modesta da taxa neutra de juros, de cerca de $9 \%$ ao ano para algo em torno de 8\% ao ano. É bom notar, contudo, que, se houve alguma nova queda no período que se seguiu à grande crise internacional de 2008, estas estimativas não teriam como capturá-la por problemas relacionados ao tamanho reduzido da amostra. Resta, pois, uma possibilidade que tenha havido queda adicional da taxa neutra de juros, a qual pode ser aferida por novas estimações.

De qualquer forma, as estimativas corroboram a noção de que a taxa neutra de juros no Brasil seria mesmo bastante elevada. É verdade que, pela abordagem seguida, o que as estimativas capturam é a taxa neutra de juros como percebida pelo Banco Central, que poderia estar errado a respeito deste parâmetro. No entanto, caso o BC seja excessivamente conservador acerca da taxa neutra (acreditando que a taxa neutra é mais alta que a verdadeira taxa neutra) é possíve $^{14}$ mostrar que a inflação ficaria sistematicamente abaixo da meta. Da mesma forma, se o BC acredita numa taxa neutra inferior à verdadeira, a inflação ficaria sistematicamente acima da meta. Isto dito, à luz da discussão anterior, não parece haver evidência de que o BC superestime a taxa neutra.

Resta, é claro, a questão do porquê de taxa neutras tão altas, para a qual não parece haver resposta definitiva. Parcela da história pode, como vimos, estar relacionada à expansão fiscal persistente observada desde a estabilização da economia em 1994. Uma hipótese promissora,

13 Detalhes do procedimento podem ser encontrados nos seguintes textos: The Rescue of the Kobayshi Maru (relatório Santander 16/nov/2009) e The Neutral Interest Rate Redux (relatório Santander, 24/Nov/2009).

14 The Neutral Interest Rate Redux (relatório Santander, 24/Nov/2009). 
ainda que, no meu conhecimento, não testada, aponta para a existência de crédito direcionado, ofertado a taxas de juros muito inferiores inclusive à taxa Selic, como um dos motivos para a necessidade de uma Selic mais alta do que a que seria requerida caso não existisse direcionamento de crédito, ou, se houvesse, fosse ofertado a taxas compatíveis com as de mercado.

Ainda que não se saiba precisamente porque o país precisa de taxas de juros tão altas para manter a inflação na meta, uma observação parece estar além da dúvida: mesmo submetido a taxas de juros que causariam recessões de grande magnitude em outros países, o consumidor brasileiro mantém taxas elevadas de crescimento, seja do consumo, seja das vendas no varejo.

GRÁFICO 9 - CONSUMO X TAXA REAL DE JUROS E VENDAS NO VAREJO X TAXA REAL DE JUROS
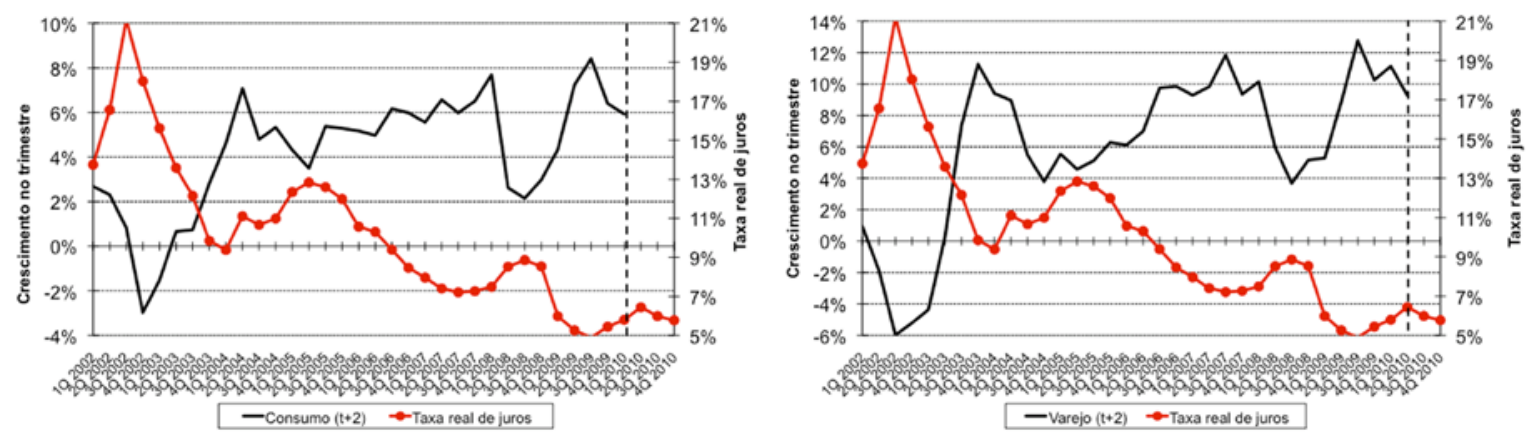

FONTES: IBGE, BCB.

Isto não significa, porém que o consumo seja insensível à taxa de juros. Pelo contrário, alterações dos níveis de taxas de juros reais (aqui o swap de 360 dias deflacionado pelas expectativas de inflação 12 meses à frente) parecem estar associados a mudanças no sentido oposto das medidas de consumo, como esperado, com uma defasagem da ordem de dois trimestres, um dos fatos estilizados frequentemente destacados pelo BC.

Em outras palavras, ainda que elevações da taxa de juros aparentemente causem desaceleração do consumo (e vice-versa), mesmo taxas de juros altas em comparação às observadas em outros países parecem ser consistentes com um ritmo forte de expansão do consumo (e da demanda em geral). Dito ainda de outra forma, as taxas elevadas de juros não aparentam ser, a priori, obstáculo para o crescimento da demanda e do produto, talvez, como notado anteriormente, pela existência de mecanismos alternativos de crédito oferecido a taxas de juros consideravelmente inferiores.

Resta examinar, por fim, outro "pecado" normalmente atribuído às altas taxas de juros no Brasil: a apreciação da moeda. Partindo da condição de paridade descoberta de taxa de juros, podemos expressar a relação entre o comportamento da taxa de câmbio $(e)$ e do diferencial 
entre juros domésticos (i) e externos $\left(i^{*}\right) \operatorname{como}^{15}$ :

$$
\log e_{t}=\log e_{t+1}+\log \left(1+i^{*}\right)-\log (1+i)
$$

Esta equação indica que, dada a expectativa quanto à taxa de câmbio futura, um aumento do diferencial entre a taxa doméstica e internacional de juros tende a apreciar a moeda. É possível argumentar, porém, que, se a taxa de câmbio tende a voltar ao equilíbrio, a taxa de câmbio esperada deve refletir, em alguma medida, os determinantes da taxa de câmbio de equilíbrio.

Num horizonte relativamente curto, no qual os ativos e passivos externos do país permanecem relativamente inalterados, podemos ligar a taxa de câmbio de equilíbrio a dois fundamentos: (a) termos de troca; e (b) o apetite dos investidores estrangeiros por ativos nacionais. A primeira variável pode, como argumentado acima, ser medida em frequência diária por alguma medida de preços de commodities, no caso o índice CRB. Já a segunda poderia ser medida por algum índice de risco soberano do Brasil, mas isto geraria problemas de endogeneidade. Assim, usamos o índice de volatilidade da bolsa nova-iorquina (VIX) como medida do "apetite global por risco", que, por tabela, deve afetar também o interesse por ativos brasileiros.

Por fim, como estamos explicando o comportamento da taxa de câmbio real-dólar, temos que controlar o efeito das alterações da paridade do dólar com respeito a outras moedas (medida pelo índice DXY). Concretamente, esperamos que movimentos de desvalorização do dólar face às demais moedas reflita-se na desvalorização do dólar também face ao real e viceversa. Assim, nosso modelo completo pode ser descrito como:

$$
\log e_{t}=\beta_{0}+\beta_{1} \log C R B+\beta_{2} \log V I X+\beta_{3} \log D X Y+\beta_{4}\left[\log (1+i)-\log \left(1+i^{*}\right)\right]
$$

Os sinais esperados dos coeficientes são dados na seguinte tabela, assim como os motivos para isso:

TABELA 2

\begin{tabular}{lll}
\hline \multicolumn{1}{c}{ Parâmetro } & \multicolumn{1}{c}{ Sinal esperado } & \multicolumn{1}{c}{ Motivo } \\
\hline$\beta_{1}$ & Negativo & Melhores termos de troca (preços de commodities) apreciam a moeda \\
$\beta_{2}$ & Positivo & Maior volatilidade (menor apetite por risco) deprecia a moeda \\
$\beta_{3}$ & Positivo & Dólar mais forte (DXY mais alto) deprecia a moeda \\
$\beta_{4}$ & Negativo & Diferencial de juros mais elevado aprecia a moeda \\
\hline
\end{tabular}

15 Maiores detalhes quanto à derivação e estimação do modelo a seguir estão em On Stones And Cannons (relatório Santander, 18/out/2010) e Slip Slidin' Away (relatório Santander, 25/out/2010). 
Os resultados da estimação aparecem na tabela abaixo ( $\mathrm{p}$-valores expressos como porcentagens).

TABELA 3

\begin{tabular}{l|rrr}
\hline \multicolumn{1}{c|}{ Parâmetro } & Variável & MQO & MGM \\
\hline$\beta_{0}$ & Constante & 1,5341 & 1,5316 \\
$\beta_{1}$ & & $0,00 \%$ & $0,84 \%$ \\
& CRB & $-0,5902$ & $-0,5899$ \\
$\beta_{2}$ & & $0,00 \%$ & $0,00 \%$ \\
$\beta_{3}$ & VIX & 0,0350 & 0,0352 \\
$\beta_{4}$ & DXY & $0,00 \%$ & $0,00 \%$ \\
$\mathrm{R}^{2}$ & & 0,5930 & 0,5932 \\
Adj. R & Diferencial de juros & $0,00 \%$ & $0,00 \%$ \\
\hline
\end{tabular}

FONTE: Alexandre Schwartsman e Tatiana Pinheiro (On Stones and Cannons).

Como o diferencial de juros é uma variável endógena, utilizamos o Método Generalizado dos Momentos, embora apresentemos, para fins de comparação, também as estimativas geradas por Mínimos Quadrados Ordinários (bastante semelhantes, diga-se). Os sinais vieram de acordo ao esperado, mostrando que tanto preços de commodities mais altos quanto juros domésticos maiores tendem a apreciar o real, enquanto um ambiente de maior volatilidade tende a depreciar a moeda, o mesmo efeito que resulta da apreciação global do dólar.

De posse, contudo, dos parâmetros estimados acima, podemos decompor os movimentos da moeda, ao longo de janelas móveis de 12 meses, devidos às alterações em cada uma das variáveis do modelo, devidamente expressos nos gráficos abaixo (Gráfico 10).

Claramente o efeito dominante vem dos movimentos de preços de commodities e do valor global do dólar, enquanto tanto os impactos do "apetite por risco" como do diferencial de juros, ainda que visíveis, são relativamente modestos. Estas mesmas conclusões persistem se, ao invés de decompor o comportamento da moeda ao longo de janelas móveis, o fizermos estabelecendo momentos iniciais: preços de commodities e o valor global do dólar desempenham o papel central no comportamento da taxa de câmbio real-dólar, deixando tanto à taxa de juros, como ao VIX, papel de coadjuvantes.

De maneira geral, portanto, a política monetária revelou-se capaz de manter a inflação ao redor da meta, ainda que a distribuição dos desvios com relação a esta última não aparente ser simétrica ao redor de zero, como a apresentada por outros países. Este fato sugere adicionalmente que, a despeito das taxas de juros brasileiras serem elevadas em comparação internacional, elas não implicaram taxas de inflação sistematicamente abaixo da meta, o que 
GRÁFICO 10 - CONTRIBUIÇÃO PARA A APRECIAÇÃO (-) OU DEPRECIAÇÃO (+) DO REAL FACE AO DÓLAR
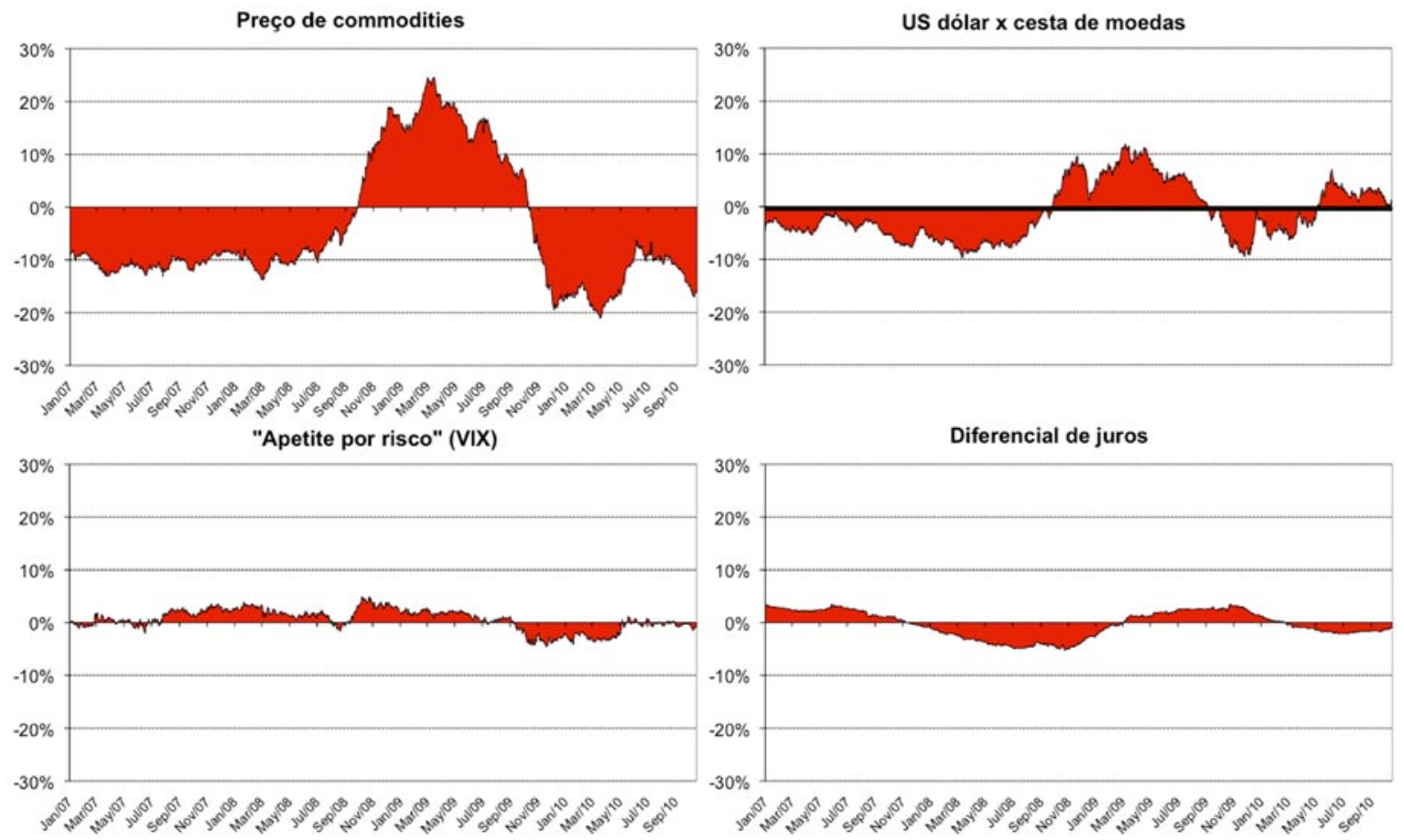

FONTE: Alexandre Schwartsman e Tatiana Pinheiro (Slip Slidin' Away).

GRÁFICO 11 - CONTRIBUIÇÃO PARA APRECIAÇÃO(-)/DEPRECIAÇÃO(+)

Contribuição para appreciação(-)/depreciação(+)

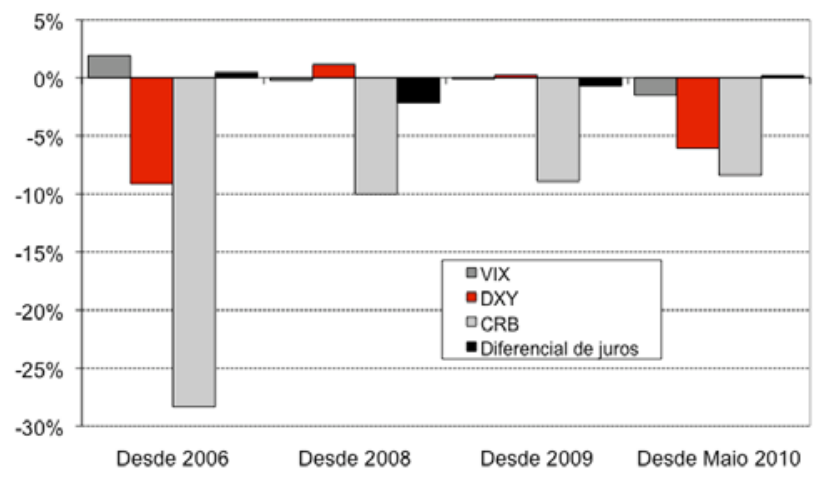

FONTE: Alexandre Schwartsman e Tatiana Pinheiro (Slip Slidin'Away).

seria um sinal de exagero do ponto de vista de condução da política monetária.

Assim, as estimativas de taxas neutras de juros também indicam que estas são elevadas: as mais recentes apontam para números ao redor de $8 \%$ ao ano, ainda que caiba reconhecer que alterações potenciais associadas à eclosão da crise internacional não puderam ser capturadas por nossos modelos.

De forma consistente com esta observação, notamos também que, embora a demanda doméstica (em particular o consumo) pareça reagir conforme o esperado a mudanças nas taxas 
reais de juros, desacelerando quando estas sobem e vice-versa, taxas relativamente elevadas de juros parecem congruentes com uma velocidade alta de expansão da demanda. Isto indica que taxas de juros aparentemente não representaram obstáculo ao crescimento da demanda interna à frente do PIB.

Por fim, mesmo que taxas de juros pareçam ter um efeito de acordo com o esperado sobre a taxa de câmbio - juros mais altos levando à apreciação da moeda e mais baixos à depreciação do câmbio - a magnitude do impacto é modesta em comparação aos efeitos oriundos de mudanças nos preços internacionais de commodities, assim como comparada aos efeitos locais da apreciação ou depreciação global do dólar.

\section{CONCLUSÃO}

Não há como escapar da conclusão que o arranjo de política econômica foi exitoso. A despeito do ceticismo prevalente em determinados círculos e ataques frequentes a que foi sujeito, o tripé macroeconômico mostrou-se mais do que consistente com a aceleração do crescimento; é bastante provável que, em conjunto com os ganhos de termos de troca, seja de fato o responsável pelo bom desempenho do país, assim como pela resistência que o Brasil apresentou quando da crise internacional.

Com tal folha de serviços prestados à Nação, seria de se esperar que a continuidade do regime estivesse assegurada. No entanto, os sinais são precisamente os opostos.

Nos dois últimos anos, a pretexto da adoção de políticas contracíclicas, observamos uma deterioração considerável das contas públicas. Se em 2009 ainda era possível atribuir o mau desempenho fiscal à queda da arrecadação por conta da queda do nível de atividade, assim como certas reduções de impostos, o comportamento da arrecadação federal em 2010 revela, além de qualquer dúvida, que houve uma piora permanente do superávit primário, particularmente do governo federal. Como chamamos a atenção acima, a expansão fiscal, truques contábeis à parte, ficou ao redor de 1,5\% do PIB.

Isto dito, apesar das juras acaloradas de que um ajuste fiscal ocorreria já em 2011, não custa nada lembrar que nem nos dois grandes episódios de aperto das contas públicas, em 1999 e 2003, houve um ajuste de magnitude capaz de reverter os danos dos dois últimos anos. Em ambas as ocasiões, mesmo contando com o auxílio de taxas de inflação bastante acima daquela que deverá se materializar nos próximos anos, a redução do gasto federal não passou de $0,7 \%$ do PIB.

Some-se a isto a expansão "parafiscal", associada ao crescimento da dívida por conta dos aportes ao BNDES e vemos que, nitidamente, a perna fiscal do tripé ficou muito enfraque- 
cida.

Já o diagnóstico sobre a política monetária é menos claro, mas há um dado revelador. Exceção feita à inflação esperada para 2009, muito influenciada pela forte desvalorização do câmbio no trimestre final de 2008, não houve desvio maior das expectativas de inflação com relação à meta como o observado no final do ano corrente. De 2005 para cá, medida já no final do ano (quando os analistas têm condições melhores de efetivamente projetar um número), a expectativa de inflação para o ano seguinte tendeu a ficar próxima à meta. Ao final de 2010 , porém, as expectativas para a inflação de 2011 mostram-se bastante acima da meta (entre 0,6\% e $0,7 \%$ ), mesmo havendo tempo hábil para que o Banco Central possa tomar medidas que revertam a trajetória da inflação.

Mesmo levando em consideração todas as restrições que possa fazer à pesquisa Focus, é de chamar a atenção a perda de credibilidade do Banco Central ao longo deste último ano. A bem da verdade, não há como avaliar agora a postura do Banco Central sob um novo governo e pode ser que o $\mathrm{BC}$ esteja certo na sua avaliação acerca dos riscos inflacionários à frente, mas o Focus sugere que, ao menos na comunidade daqueles que contribuem para a pesquisa do BC, a autoridade monetária está sub judice.

Concluímos, portanto, que temos vivido nos últimos anos uma mudança, não tão lenta, nem tão imperceptível na orientação geral de política econômica. Minha visão é que estas alterações vieram para ficar e que, portanto, o melhor guia para a política econômica dos próximos quatro anos é o ocorrido nos últimos dois. Espero estar errado, mas não contaria com isto. 